\title{
Leadership and New Ways of Working: A Case Study in a Financial Service Organisation
}

\author{
Stoffers J., Kurstjens J., Schrijver I. \\ Research Centre of Employability, Zuyd University of Applied Sciences, Heerlen-Maastricht-Sittard, the Netherlands \\ Email address: \\ jol.stoffers@zuyd.nl (Stoffers J.)
}

\section{To cite this article:}

Stoffers J., Kurstjens J., Schrijver I.. Leadership and New Ways of Working: A Case Study in a Financial Service Organisation. International Journal of Business and Economics Research. Vol. 4, No. 3, 2015, pp. 157-162. doi: 10.11648/j.ijber.20150403.18

\begin{abstract}
In financial service organisations clients are imposing increasingly greater demands on staff. The organisations need to find a balance between, on the one hand, "being in control", and promoting staff responsibility, flexibility and enterprise on the other. Managers have a crucial role in this process and their leadership is assumed to have an influence on how New Ways of Working (NWW) are applied by employees. New working patterns could offer space to staff to demonstrate and further develop their competences (organising their own work and goals; showcasing independence, determination, goalorientation, communication, flexible behaviour and collaboration). NWW is aimed at staff flexibility and the utilisation of new technical developments in order to work independently of time and place, and thereby being of even greater service to the client. The leadership style in the financial service sector is primarily task-oriented, and this is also included in the organisation where this case study was conducted. It is apparent from this study that a task-oriented leadership style does not contribute to NWW, although this is dependent on the nature of the department and the type of roles. The recommendation, based partly on the literature, is to invest in another style of leadership: the person-centred leadership style.
\end{abstract}

Keywords: New Ways of Working, Task-Oriented Leadership, Person-Centred Leadership, Staff Competence

\section{Introduction}

There has been a change in client behaviour among consumers. Clients are increasingly expecting to be able to determine when, where and how they wish to conduct business with organisations $[1,2]$. A new way of working is necessary in order to be able to adequately respond to this.

New Ways of Working aspires to separate the constraints of time and place from staff flexibility and the usage of innovative technical developments, thus supplying a unique service to the client. In addition to this, NWW offers staff the opportunity to combine work and home life better, enabling them to work more flexibly, as well as further their personal development [3]. This links in to the trend that from an employees' perspective staff are now also expecting different opportunities than in the past. They attach greater value to flexibility and development opportunities $[4,5]$, for instance.

The financial service sector requires a stricter organisation process in order to promote client satisfaction. However, this leads to friction in terms of employee independence and flexibility and clients' wishes for more flexibility.

The ability to exercise the power of "being in control", whilst also taking into account and encouraging staff responsibility, flexibility and entrepreneurship is a skill organisations need to have in the financial service sector. Managers have a crucial role here as their leadership style has an influence on NWW.

New ways of working propose a wider scope for staff to exhibit and evolve their individual competences.

The remainder of this article is structured as follows. Firstly, the focus will be on the literature around the NWW topic and the four NWW pillars. Subsequently, the research question and hypotheses will be addressed, followed by the results of the study. The results will be used to arrive at a conclusion, and finally the practical relevance of the study will be considered along with suggestions for further research.

\section{New Ways of Working (NWW)}

There are numerous definitions for "The New Way of Working" (NWW) [3,6], and where previous management philosophies have emphasised the optimisation of the work process [2], NWW places the emphasis on the result [5].

Bijl's [7] is as follows: "NWW is a vision whereby recent developments in information technology act as a catalyst for 
a better design and management of knowledge work. This involves the reconstruction of the physical work place, the organisational structure and culture, the management style and, lest we forget, the mentality of the knowledge worker and his manager" [7]. Bijl's definition [7] encompasses all other definitions as it includes the four most important focus areas (people, organisation, work environment and technology). The emphasis NWW places on the result demands a different organisation of the work place, the organisational structure and the style of leadership. Additionally, the current technology offers the opportunity to work without the restriction of time or location [7].

In order to be able to implement NWW, the work concerned should involve knowledge work, a lower emphasis on an individual's physical presence at work and staff should be willing (motivation) and able (competence) to apply NWW.

De Leede and Kraijenbrink [8] have also outlined four important conditions for working, according to NWW, and achieving positive results. These are: trust between colleagues, trust between employees-supervisors, social cohesion and result-oriented leadership. According to De Leede and Kraijenbrink, [8] trust and social cohesion may be seen as mediators by demonstrating the result of NWW on an organisation's performance.

There are both benefits and disadvantages to NWW. The benefits are cost savings and increased profits. Costs savings come about through $[7,8]$ lower office accommodation costs, a reduction in staff costs through a decrease in travel costs, a reduction in sickness absences [5], fewer personnel through higher productivity and a reduction in IT costs.

Profit increases result from, for instance, added value [3] from increased employee satisfaction, increased customer satisfaction, a better use of work potential, an improvement of the employer's image and a contribution to society through sustainable enterprise. As outlined above, De Leede and Kraijenbrink [8] suggest that improved performance can only be achieved where there is trust and social cohesion present in the organisation.

There are also disadvantages to take into account. One disadvantage of NWW is that staff may actually lose the balance between work and home life. As they are able to work anywhere, they will. As a consequence, the balance is lost $[3,7]$. Another disadvantage is that it has a negative effect on the social relationships between people. People would have less face-to-face interaction, so the focus, which should be mainly on the task and the human aspect, becomes lost because there is less social cohesion to begin with [3,7]. A third disadvantage is that, despite the fact that NWW is technically possible, it usually meets with resistance when it is introduced. Erasmus University [9] has underlined three obstacles to introducing NWW, including staff anxiety about losing a permanent desk space or contact with colleagues, significant resistance by managers to change their management style due to a lack of trust in competences of their staff or the organisational culture that does not fit in with NWW.
Four focus areas have been highlighted for NWW [7,10, and 11]. These four pillars are:

1. The individual: this includes elements such as motivation and competence (development)

2. The organisation: this includes organisational structure, organisational culture and leadership style.

3. The work environment: this includes office space and design.

4. The technology: this includes ICT equipment and support.

According to Bijl [10], there is a relationship between the four focus areas described above, and change or renewal is required in all four areas in order to achieve the NWW objective.

\subsection{The Individual and Competence (Development)}

On the basis of the literature there are a number of skills that can be identified as prerequisites to realise the style of work appropriate for NWW [7]. According to Stam [12], the most important skills are: managing staff, organising one's own work, commitment, networking, independence, decision-making skills, goal-orientation, communication, flexible behaviour and collaboration. It is important for the organisation to aim at the development of the abovementioned abilities in order to encourage NWW [13].

NWW supplies the advantage of allowing staff to advance their abilities such as responsibility, flexibility and enterprise. [7]. These abilities contribute to satisfying the increasing demand of client expectations. It is without a doubt that this is an important condition to be distinctive within the financial service sector.

\subsection{Organization}

Three elements are bound together within the organisation: vision/ambition, organisational structure and organisational culture $[7,8]$.

Vision and ambition reflect the aim and direction of the organisation. It is necessary for the organisation to formulate a vision and ambition in respect of NWW in order to motivate staff and implement NWW successfully. This vision and ambition should represent an extension of the organisational strategy [7].

The arrival of NWW may mean that new organisational structures are required. Within this process there is a move towards network structures, in which there are self-evident or emphatic collaborative relationships between independent organisations, or mutually between individuals, as well as self-management, self-organisation, enterprise and exchange of information with the aid of ICT [7,14]. Organisational culture relates both to how individuals within the organisation want to interact [7] and to how they actually communicate and collaborate with each other [15]. These have to correspond, and leadership plays an important role in this $[2,15$, and 16$]$.

The style of management determines a significant part of the culture within an organisation [17]. NWW ensures for the 
need of person-centred leadership, staff support, collaboration, and the realisation of connections with staff. $[7,10]$.

\subsection{Technology}

NWW requires that ICT helps staff to be more productive, more creative and more flexible. The implementation process of NWW is able to run more smoothly once technology has been applied in the organisation both internally and externally [18]. ICT is the one pillar providing us with the opportunity to arrange encounters that are independent of time and place [19]. However, technology is not the engine within NWW, but it enables and facilitates it [5]. Bijl [7] describes ICT as a catalyst and a driving force. ICT is primarily the communication technology that enables collaboration and communication [5], which can contribute to enhance social cohesion [8].

\subsection{Work Environment}

An organisation may opt to introduce only parts of NWW [5]. Partial implementation of NWW leads to a hybrid organisation in which components of a traditional organisation are combined with those following NWW [12].

NWW is aimed at working methods that are free of the constraints of time and place. The employee tailors his work to the working environment. Work is undertaken within the organisation with flexible work spaces customised specifically to various sorts of activities [7,10, and 15]. The office is often no longer the primary work environment, rather it is a meeting place for staff. Essers [19] describes "the office as sitting in the employees' bag". He refers to this as "the mobile office" which is geared to the employee's work.

It is of importance for employees to remain connected, and the office within the organisation is often the "home location" and binding agent for staff [3]. This location is designed in such a way that staff gladly physically meet each other there to work together [7].

\section{Leadership Style}

As described earlier leadership style determines the organisational culture to a significant degree. The factors of communication and collaboration, both perceived by the staff and the actual representation, are components of organisation culture. [15]. These have to correspond, and leadership plays an important role in this [2, 15, and 16].

Since the 1940s, leadership behaviour has been a key issue and a distinction is being drawn between task-oriented and person-centred leadership styles [20,21]. Therefore in this study a distinction will be made between task-oriented and person-centred leadership styles.

According to Kluytmans [22] and Taberno [23] taskoriented leadership refers to the degree to which the leader takes the initiative for activities within the group. This manager leads and says what has to happen, often including the best way to do so and is actively involved in the performance of the work. Person-centred leadership pertains to the level to which the manager proves to be attentive to the well being of his staff. This manager shows great appreciation for work that is carried out properly, emphasises the difference in work satisfaction and enhances the sense of self-worth amongst staff by treating them all as equals $[22,23]$.

Bijl $[7,10]$ has suggested that NWW leads to a need for person-centred leadership, staff support, the realisation of connections with staff and collaboration. De Leede and Kraijenbrink [8], on the other hand, suggest that there is a need for results-oriented leadership which corresponds to task-oriented leadership. This will be explored in further detail in this study, as task-oriented leadership is the most common form of leadership within the financial sector where the study is to be conducted.

New working ways should offer staff the room to demonstrate and establish important competences such as responsibility, flexibility and entrepreneurship [7].

The research question will be explored using the two following hypotheses:

Hypothesis 1: Task-oriented leadership has a negative effect on "New Ways of Working" (see also figure 1).

Hypothesis 2: "New Ways of Working" has a positive effect on staff competence (see also figure 2).

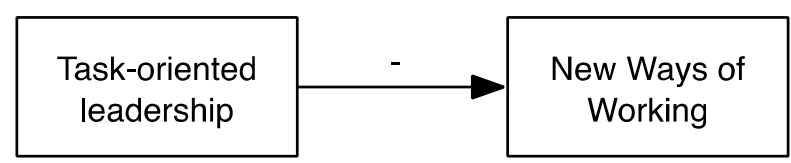

Figure 1. Relationship between Task-oriented Leadership and New Ways of Working.

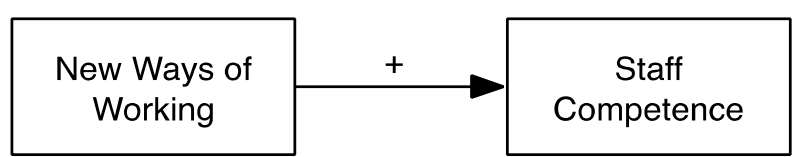

Figure 2. Relationship between New Ways of Working and Staff Competence.

\section{Methodology}

The research methodology is a case study. We opted for this strategy, as this organisation is a typical case of financial service industry in the Netherlands. Case studies may be used for different types of research purposes, including theory development and theory testing, in which key variables and their links are identified and described [24,25]. A quantitative method was adopted in this study as - along with objectivity and the avoidance of selective observations - this provides the opportunity to approach multiple respondents [26]. The study was undertaken at a financial service organisation in the south of the Netherlands at the Sales \& Service and Financial Advice departments. This study included deductive research methods, given that hypotheses were formulated on the basis of a literature review which were subsequently tested in the study. The use of a survey is particularly appropriate for deductive research, as this provides an 
accessible and manageable way to collect and explain data. Furthermore, a snapshot approach or cross-sectional study design was employed as the study was conducted at a specific moment in time. As such, there was no time available to conduct a longitudinal study. It was also desirable to know the state of affairs at this specific moment in order to be able to take action in the short term.

Validated questionnaires (validity reflects whether the research is actually measuring what it is supposed to measure) [25] were used in order to increase reliability (the extent to which the collection of data, the techniques used and the analysis ensured for interdependent findings) [25]. Stam's validated questionnaires comprising of different components were used in this study [12].

The NWW environment organisational scan was used to determine to what extent staff were working according to the "New Ways of Working". A maximum of 12 points may be scored in this questionnaire. 0 to 4 points equates to the traditional work environment; a score between 5 to 8 is equivalent to a hybrid organisation; and a score between 9 and 12 reflects an NWW environment.

The leadership questionnaire consists of two parts: the first is only completed by the managers and measures how they view themselves: more person-centred or more task-oriented. The second part determines how staff view their managers; the scores here may also lie between person-centred and taskoriented.

The final questionnaire covered the NWW skills. Stam [12] has defined a number of competences on the basis of a literature review which fit best within the "New Ways of Working": organising one's own work, commitment, networking, independence, decision-making skills, resultorientation, communication, flexible behaviour and collaboration. The actual competence of an employee is not measured when determining competence, rather the extent to which the employee feels there is space to demonstrate this competence and the degree to which the organisation offers room in its policies for this competence to be demonstrated is measured. For instance, it may be that an employee is in fact highly flexible, but is unable to demonstrate this flexibility due to the nature of his or her position.

The questionnaires were sent with an introductory letter explaining the aim of the study and the anonymity of the answers. The list of concepts that was used was also required alongside the questions in order to give clarification.

Homogeneity of the questionnaire is an important part of reliability. Cronbach's alpha was used to determine whether the collection of data was homogeneous [26]. The internal reliability of the leadership style questionnaire completed by managers was inadequate $(\alpha=.590)$. The reliability of the leadership style questionnaire completed by non-managerial staff was also inadequate $(\alpha=0.648)$. The reliability of Stam's competences questionnaire [12] was good $(\alpha=.864)$.

\section{Results}

All of the 101 employees of the Sales \& Service and
Financial Advice departments were requested to fill out the questionnaire. In total, 71 completed questionnaires were returned, meaning the response percentage is $70 \%$. 32 respondents (approximately 45\%) were employed in the Sales \& Service department and 38 respondents (approximately 54\%) in the Financial Advice department. One respondent $(1.41 \%)$ worked in both departments. $31 \%$ of the respondents from the Sales \& Service department were male; for the Financial Advice department this was $45 \%$. The average age of respondents in the Sales \& Service department was $43.44(\mathrm{SD}=11.98)$, for the Financial Advice department this was $38.83(\mathrm{SD}=8.71)$. Furthermore, the average number of years in service was $18.17(\mathrm{SD}=14.52)$ for the Sales \& Service department, and 13.18 (SD = 9.14) for the Financial Advice department. 83.1\% of respondents were employed for more than 28 hours per week.

Approximately half $(49.3 \%)$ of the 71 respondents had completed higher professional education $(42.3 \%)$ or higher academic education $(7 \%)$. This contrasted with $50.3 \%$ of respondents who had completed vocational secondary education. Of the 35 respondents who had completed higher education $22(62.85 \%)$ were employed within the Financial Advice department. The results of the NWW environment organisation scan [17] revealed a score of $8.033(\mathrm{SD}=1.83)$ indicating that it was a hybrid organisation. When the results were analysed by the department approximately half of the respondents in Financial Advice were of the opinion that there was an "NWW Environment" in place and the other half believed there to be a hybrid organisation. In the Sales \& Service department the distribution of scores was $30 \%$ for an NWW organisation and $70 \%$ for a hybrid organisation.

It was apparent from this case study that the work environment and technology pillars [7,10,11] fulfilled staff expectations to the greatest extent in respect of NWW. Further focus is still required, and there are opportunities for development in terms of the individual and organisation pillars $[7,10,11]$.

The results of the questionnaires demonstrated to managers that they allocated themselves a higher score in terms of person-centred leadership than their staff. In respect of the components relating to task-oriented leadership, the opposite occurred: managers viewed themselves as less taskoriented than their staff.

Turning to the departments, it was noticeable that $36.6 \%$ of the Sales \& Service department experienced the style of their managers as person-centred. In the Financial Advice department this percentage was $38.2 \%$.

In the Sales \& Service department the correlation between a task-oriented leadership style and "New Ways of Working" was 0.10 , and a task-oriented leadership style explained $1 \%$ of the variance in "New Ways of Working". Table 1 shows that a task-oriented leadership style did not have a significant effect $(\mathrm{p}>0.05)$ on "New Ways of Working" $(\mathrm{B}=-0.03$; Standard Error $=0.07)$. There is therefore no relationship in this department between a task-oriented leadership style and "The New Ways of Working". 
Table 1. The effect of task-oriented leadership on NWW (Sales \& Service; $n$ $=23)$.

\begin{tabular}{llllll}
\hline & B & Standard error & B & t & p \\
\hline $\begin{array}{l}\text { Task-oriented } \\
\text { leadership }\end{array}$ & -0.03 & 0.07 & -0.10 & -0.44 & 0.67 \\
\hline
\end{tabular}

In the Financial Advice department the correlation between a task-oriented leadership style and "New Ways of Working" was 0.40 , and a task-oriented leadership style explained $16 \%$ of the variance in "New Ways of Working" within that department. It may be seen from Table 2 that there is a significant negative linear relationship between a task-oriented leadership style $(\mathrm{p}<0.05)$ on "New Ways of Working") $(\mathrm{B}=0.20$; Standard Error $=0.09)$. There is therefore a negative association between task-oriented leadership style and "The New Ways of Working" in this department.

Table 2. The effect of task-oriented leadership on NWW (Financial Advice; $n$ $=31$ ).

\begin{tabular}{llllll}
\hline & B & Standard error & B & t & p \\
\hline $\begin{array}{l}\text { Task-oriented } \\
\text { leadership }\end{array}$ & -0.20 & 0.09 & -0.40 & -2.33 & 0.03 \\
\hline
\end{tabular}

This is partially supportive of Hypothesis 1 . Task-oriented leadership has no influence on NWW in the Sales \& Service department, in contrast to the Financial Advice department where there is an effect. Apparently, the nature of the work and the type of staff have an influence as to whether or not task-oriented leadership has an effect on NWW.

Hypothesis 2, the supposition that new working ways should be able to offer staff room to demonstrate and further develop competences such as responsibility, flexibility and entrepreneurship, could not be confirmed in this case study.

\section{Discussion and Conclusion}

This case study at a financial service organisation confirms that task-oriented leadership does not contribute to NWW [7], although it has become apparent that whether the leadership style effects NWW is dependent on the nature of the work and the type of staff involved. According to Shahabi [27] there is a negative relationship between task-oriented leadership and an organisation's results.

The hypothesis that NWW should be able to offer staff further room to demonstrate and further develop competences such as responsibility, flexibility and entrepreneurship, could not be confirmed on the basis of this case study.

There is therefore a difference between the literature in this area and the results. Theory suggests that NWW satisfies employees' needs and wishes [12]. This leads to greater degrees of motivation within staff [3] resulting in the development of competences necessary for NWW, such as flexible behaviour [12]. The expectation created by the literature is therefore not fulfilled in practice. It is possible that the work processes within the organisation do not allow for the sufficient development of these competences.
Over recent years there has been a significant amount of research into the nature of NWW. To date little is known about the full impact of NWW within organisations or the relationships between its components. However, positive effects on the sub-components have been reported [3]. This study has provided an insight into the effect of task-oriented leadership on NWW and the relationship between NWW and the scope to which staff can demonstrate and develop their competences in organisations within the financial service sector.

Further research could focus on the effects of NWW on organisations' results. Numerous companies have started to implement NWW and a significant amount of research has been published in terms of the implementation of this process However, when we look at the effects of the implementation of NWW there has is very little to no information available. Other areas on which NWW could have a positive effect are employee satisfaction, the use of employee potential and the enhancement of employer image [7].

A better insight into the effects of NWW on an organisation and its results may help organisations to make a better informed choice of whether or not to implement NWW. More insight could also be obtained in respect of the mediating effect of NWW in the relationship between leadership style and the development of staff competences. Research should also be conducted within other sectors in order to provide an inter-sectoral answer to the research question.

Finally, this study undertook specific research into taskoriented leadership. Future research should reveal the presumed positive effect of person-centred leadership on NWW.

\section{References}

[1] Kotler, P., Kartajaya, H., Setiawan, I., (2010). Marketing 3.0: Vind de klik met je klant [Marketing 3.0: From products to customers to the human spirit]. Den Haag: Sdu Publishers bv.

[2] Keuning, D., (2007). Structuur doorzien [Structure seen]. Groningen: Wolters Noordhoff.

[3] Baane, R. H., Houtkamp, p., Knotter, M., (2010). Het nieuwe werken ontrafeld [New ways of working figured out]. Assen: Koninklijke Van Gorcum.

[4] Hameeteman, R., (2009). De kracht van mensen: Organiseren in de 21 ste eeuw [The power of people: Organising in the $21^{\text {st }}$ century]. Zaltbommel: Haystack.

[5] Haterd van de, B., (2010). Werken nieuwe stijl [Working on a new style]. Amersfoort: A.W. Bruna Publishers B.V.

[6] Volberda, H., Jansen, J., Tempelaar, M., Heij, K., (2011). Monitoren van sociale innovatie: Slimmer werken, dynamisch managen en flexible organiseren: Monitoring social innovation: working smarter, dynamic management and organising flexible. Magazine for HRM, 1 , 85-110.

[7] Bijl, D., (2009). Aan de slag met het nieuwe werken [Let's get to the new ways of working]. Zeewolde: Par CC. 
[8] De Leede, J., \& Kraijenbrink, J. (2014). The Mediating Role of Trust and Social Cohesion in the Effects of New Ways of Working: A Dutch Case Study. Human Resource Management, Social Innovation and Technology (Advanced Series in Management, Volume 14) Emerald Group Publishing Limited, 14, 3-20.

[9] Erasmus Universiteit, (2012). De staat van het nieuwe werken: Resultaten van de Nationale HNW Barometer 2012 [The state of new ways of working: Results of the national NWW Barometer 2012]. Rotterdam: Rotterdam School of Management Erasmus University.

[10] Bijl, D., (2007). Het nieuwe werken: Op weg naar een productieve kenniseconomie [New Ways of working: heading for a productive knowledge economy]. Den Haag: Sdu Publishers bv.

[11] Blok, M. M., Groenesteijn, L., Schelvis, R., \& Vink, P. (2012). New ways of working: does flexibility in time and location of work change work behavior and affect business outcomes?. Work: A Journal of Prevention, Assessment and Rehabilitation, 41, 5075-5080.

[12] Stam, P., (2011). Het nieuwe werken meegewogen [New ways of working weighed in]. Utrecht: Utrecht University.

[13] Pierik, C., (2009). Talentmanagement: Hét middel om vitaal te blijven [Talentmanagement: the tool to remain vital]. Het Grootste Vaktijdschrift over Bedrijfsgezondheid [The largest magazine about organizational health], nr. 5, 8-11.

[14] Kuipers, H., Amelsvoort, P. van, Kramer, E.H., (2010). Het nieuwe organisatie: Alternatieven voor de bureaucratie [New ways of organizing: Alternatives for bureaucracy]. Leuven: Acco.

[15] Egmond van, H., (2010). Het nieuwe werken: Van visie naar praktijk [New ways of working: From vision to practice]. Alphen aan den Rijn: Kluwer.

[16] Cameron, K. S., Quinn, R. E., (2008). Onderzoeken en veranderen van organisatiecultuur [Researching and changing organizational culture]. Den Haag: Sdu Publishers bv.

[17] Bos, R. T., \& Ham, M. V., (1994). De manager leer- en praktijkboek [The manager learning- and practicebook]. Den Haag: Reed Business Information
[18] Wensing, L., (2009). Technologie is en blijft de sleutel tot het nieuwe werken [Technology is and remains the key to New Ways of Working]. Reviewed on: http://hetnieuwewerkenblog.nl/technologie-sleutel-hetnieuwe-werken/

[19] Essers, G., (2010). Slimmer werken met het kantoor in je tas [Work smarter with the office in your bag]. Den Haag: Sdu Publishers bv.

[20] Stogdill, R. M., \& Coons, A. E. (1957). Leader behavior: Its description and measurement. Columbus, OH: Bureau of Business Research, The Ohio State University.

[21] Likert, R. (1961). New patterns of management. New York: McGraw-Hill.

[22] Kluytmans, F., (2005). Leerboek personeelsmanagement [Learning book human resource management]. Groningen: Wolters-Noordhoff.

[23] Taberno, C., Chambel, M.J., Curral, L., Arana, J.M., (2009). The role of task-oriented versus relationship-oriented leadership on normative contract and group performance. Social behavior and personality, 37(10), p. 1391-1404. doi: 10.2224/sbp.2009.37.10.1391.

[24] Saunders, M., Lewis, P., Thornhill, A., (2012). Research methods for business students. Harlow, England: Pearson Education Ltd.

[25] Saunders, M., Lewis, P., Thornhill, A., Booij, M., Verckens, J. P., (2011). Methoden en technieken van onderzoek [Methods and techniques of research]. Amsterdam: Pearson Education Benelux.

[26] Buuren, H. v., Hummel, H., Berkhout, J., Slootmaker, A., (2009). Onderzoek: De basis [Research the basis]. Groningen/Houten: Noordhoff Publishers bv.

[27] Shahabi, M., (2011). Leiders van het nieuwe werken: Impact van het nieuwe werken op leiderschap in de publieke en private sector [Leaders of new ways of working: Impact of new ways of working on leadership in the public and private branch]. Tilburg: Tilburg University. 